\title{
A Shift from Spectator to Creator: A Study of Blog Writing in a Print and Photo High School Class
}

\author{
Arne Olav Nygard*, \\ University of Stavanger, National Centre for Reading Education and Reading Research, \\ Stavanger, Norway
}

\begin{abstract}
This article is a study of written blog texts from 12 third grade high school students produced during one academic year, commenting on their photos and artwork as part of their curriculum in the discipline Print and Photo. The article aims to capture a change in how the students position themselves as photographers in their blog texts from the beginning towards the end of the academic year. An initial hypothesis is that the students develop a disciplinary language throughout one year of writing about their photo activities. This hypothesis is the basis for the research question: Throughout one year of blogging, is there a change in the students' writing with a focus on how they through resources in language construe a perspective on their role as participants in a discipline or profession? Analysis of the texts shows that there is a clear tendency to reduce constructions with forms of to be from the beginning towards the end of the academic year, whereas constructions with forms of to have increase in the same time span. This finding is detailed by analyzing one of the students' texts, finding a shift from predominantly descriptive accounts of the images to using language to position themselves as active participants focusing on the process of composition. Examining the distribution of abstract versus concrete nouns in the same texts shows that the frequency of abstracts nouns stays the same whereas there is a reduced frequency of concrete nouns. These findings suggest a change in the students' language from descriptions of elements in their photos into a particular kind of abstraction where the students discuss their photos in terms of how they compose the images. This change in language use suggests a shift in the students' positions from spectators to creators.
\end{abstract}

Keywords: Blog; disciplinary literacy; systemic functional grammar

Received: August, 2016; Accepted: March, 2017; Published: September, 2017

\section{Introduction}

In this article, I investigate how one Norwegian senior high school class uses blogs as a platform for developing a disciplinary literacy in the discipline Print and Photo. This discipline is a so-called "optional program subject" that students can choose

${ }^{\star}$ Correspondence to: Arne Olav Nygard, University of Stavanger, National Centre for Reading Education and Reading Research, N-4036 Stavanger, Norway. Email: arne.o.nygard@uis.no 
over other subjects in the last (third) year of a general-studies program, preparing for further studies e.g. at a university. The 14 students (of which I omitted two, a choice I will explain below) in this Print and Photo class was thus a part of a larger group of 28 students, where the other students opted for other optional program subjects.

My research interest is motivated both from close reading the blog texts as well as from observations of the class and interviews with the students, giving an account of their experience with using blogs in Print and Photo. The class and their teacher used blogs as a hub for all classroom activities in Print and Photo during the academic year 2009-2010. Both the teacher and the students had individual blogs, and every blog was published openly on the web. The students used the blogs to respond to assignments posted on the teacher's blog, and the teacher also encouraged the students to publish blog entries outside of the mandatory assignments (accounted for in Nygard (2013)).

I observed the students over a period of three months during the spring of 2010 , followed by interviews with the students. In the interviews, the students discussed values and attitudes related to uses of literacy and technologies of literacy in different situations, in school and outside school, both for personal use and for school-related work. Findings from the interviews are grouped into three main topics: (i) community and sharing, (ii) motivational factors, and (iii) organizational factors:

(i) The students and their teacher established a sense of community through their blogs, using this community of blogs to share ideas and seek inspiration. Moreover, the culture of open publication imposed certain standards for what the students published, reporting that they did not want to expose substandard work openly;

(ii) The students were motivated by having an actual audience to write for. In addition, they contrasted the blog language, characterized as "less formal," "shorter" and more "true," with the academic language of "ordinary school," which they characterized as constraining and rigid;

(iii) the blogs had significance for the students as their personal tool for organizing knowledge and making sense of the world around them-as part of their "technology of thought" (Barton, 2007).

The present article investigates how these students establish a language on their blogs for describing their disciplinary activities across one academic year. Much literature on blog texts focus on the blog as a new text and genre phenomenon occurring in digital media (Blood, 2000; Miller \& Shepherd, 2004; Rettberg, 2014). Some studies on the use of blogs in education study blog writing from the perspective of identities, roles and relations (Kjellberg, 2009; Vasudevan, Schultz, \& Bateman, 2010). Other studies of educational blogs are rhetorical and genre studies (Grüters, 2011; Kløve Juuhl, 2014), and although most studies take an interest in what is new in blogging, some explicitly address technological affordances in one way or the other (Grüters, 2011; Kjellberg, 2009; Oravec, 2003). There are studies that take explicit interest in language use, but studies often base their research on questionnaires and student 
self-reporting or discussions of advantages of blogging for language use, rather than analysis of language (Amir, Ismail, \& Hussin, 2011; Nadrah Abu Bakar, Hafizah Latif, \& Azizah Ya'acob, 2010; Soares, 2008). Still, some investigate blog language, such as Doodstar's (2004) study of vulgarity in a blog controversy with a particular linguistic focus and Fellner and Apple's (2006) study of word frequencies in university level language learner's blogs in a developmental perspective. Some studies explicitly investigate how the blog impacts writing in academic settings, investigating the blog's affordances for various ways of collaborative writing and peer comments, for writing drafts and as a tool for scaffolding during writing instruction (Wong \& Hew, 2010, Chen, Liu, Shih, Wu, \& Yuan, 2011; Sullivan \& Longnecker, 2014; Novakovich, 2016;). Findings were that comments from peers improved the quality of writing, the students took a positive attitude towards giving and receiving feedback (Chen et al., 2011), and the feedback on the blog was perceived as more critical and directive than feedback in traditional settings, correlating positively with the quality of the writing (Novakovich, 2016). Moreover, drafting texts on the blog in addition to being scaffolded by the teacher contributed to better quality in the texts (Wong \& Hew, 2010; Novakovich, 2016). Several studies also highlight the value of writing for an audience (Lee, 2010; Sullivan \& Longnecker, 2014; Novakovich, 2016), as well as the values of the sense of community created by the blogs, affecting positively the way in which bloggers write (Akbulut \& Kivici, 2007; Utecht, 2007; Farmer et al., 2008). Some studies are critical of claims that the blog improves writing, comparing blogging with conventional writing tools and finding no significant differences in writing skills (Chen, 2016; Fischer, Haley, Saarinen, \& Chretien, 2011; Lin, 2014).

\section{Establishing a blog culture}

Several studies that take interest in blog writing discuss the blog as enabling new social spaces for literacy that diverges from traditional schooling, but few studies investigate the functions of language in classroom blogs. Also, most studies of blogging in academia study blogs as a time-limited side-project, as a supplement to traditional approaches to literacy. This is discussed by O'Donnell (2006), who argues that blogging, rather than being seen as a technological tool for learning, should be seen "[...] as a situated practice that must be brought into appropriate alignment with particular and pedagogical and disciplinary practices," using it across the curriculum. The present study is a case of a class incorporating the blog into the syllabi, aiming to use the blog as literacy tool that differs from the traditional tools and forms of using literacy in school. In this case, in other words, rather than just using the blog as a side-activity, the class established a literacy culture closely related to the blog as new, digital text cultural phenomenon. Moreover, they valued this culture of blogging highly, arguing that it affected learning and literacy positively. Taking these textcultural factors as well as the students' reports on the value of blogging in class into account, I have close read the students blog texts, hypothesizing that the students developed a disciplinary language throughout the year of using the blog to write about their curricular activities. 
This is the basis for the research question: Throughout one year of blogging, is there a development in the students' writing with a focus on how they through resources in language construe a perspective on their role as participants in a discipline or profession?

The article is structured in three sections. First, I present the material and methodology as well as outlining a social semiotic perspective of language to propose a theoretical approach to an analysis of the blog language. Second, the results of the analysis are presented, and finally the results are discussed.

\section{Methodology and Material}

As my interest is in the linguistic choices students make on their blogs, I find a useful theoretical point of departure in concepts from social semiotics, primarily systemic functional linguistics (Andersen \& Holsting, 2015; Knain, 2014; Maagerø, 2005; Matthiessen \& Halliday, 2014). The primary material for this study are blog posts from a senior high school class of 14 during one year of blogging in the discipline Print and Photo, from the academic year 2009-2010. The students value highly the blogging activities and the impact the blogs have on their writing, so I consider the observations and interviews as supportive sources informing the text analysis. As the text analyses rely on language specific software searches for words and sentences, implicating the use of language specific dictionaries, I have omitted two blogs in class that are written in English rather than Norwegian, reducing the number of blogs to 12. To further reduce the complexity of the material and to make a close analysis of the blog texts manageable, I narrow the analysis to one assignment type that is given four times during the academic year. I focus on the first and the last of these assignments, from September 2009 and May 2010 respectively, which means that one assignment is close to the start of the academic year and one is close to the end. The assignment type is called " 5 Categories." The teacher publishes the assignment texts on her blog, suggesting different, usually broad categories (such as "Animal," "Portrait," "Weather," and "Age") for each assignment. The students are instructed to take as many photos as they wish to these categories, select two photos from each category, and present and comment on these photos on their individual blogs. These assignments are representative of their disciplinary activities both in that they are major assignments given four times during the academic year, as well as in that they focus on photography, on which they spend most of the time working.

Furthermore, I narrow the analysis to the sections of the students' texts where they explicitly account for their compositional choices. The students respond to the teacher's assignment texts in a formulaic way, providing it an easy task to single out those parts of the texts that describe composition. These sections are the most extensive parts of their writing and the place where they use disciplinary specific language for describing their images in terms of photographic features, artistic and compositional ideas and ambitions. In other words, these sections of their texts are especially tied to what they learn as photographers throughout the year, and it is here they get to formulate this in writing about pictures they take and choose to display. 
I work from the assumption that in a study of how the students develop a disciplinary literacy, these sections are of particular interest. The textual material, then, is comprised of written texts commenting on 20 images, ten from September 2009 and ten from May 2010, from a total of 12 students.

In their texts, they have the opportunity to give explanations for their choices of motif and give explanations and reasons for their compositional and technological choices, with an awareness of a presumably interested audience (as discussed in Nygard (2013)). The students' language, in other words, performs certain functions in a specific context: Their texts are simultaneously responses to an assignment given by the teacher aiming to meet the teacher's requirements; presentations of their artwork to an interested audience; explanations of technical and compositional choices they have made; and interpretations and evaluations of their pictures.

\section{Systemic functional linguistics}

Systemic functional linguistics (SFL) is a theory of how language is constructed in social settings through grammar; experience is construed into meaning (Maagerø, 2005; Knain, 2014; Mathiessen \& Halliday, 2014). A central concept explaining how language contributes to this construal is the idea of the three metafunctions: The ideational metafunction (encompassing the experiential and logical metafunctions) construes experience to thematic meaning representing some kind of reality; the interpersonal metafunction shapes social relations, and the textual metafunction weaves meaning into a cohesive whole. I will dwell on the ideational metafunction in more detail below, specifically the part of the ideational metafunction called the experiential metafunction.

\section{Compositional choices: the experiential metafunction}

As mentioned above, I take interest in the sections of the students' texts where they explicitly focus on their compositional choices. These sections aim to describe concrete features of their pictures, which can be said to correspond meaningfully to the experiential metafunction. The experiential metafunction focuses on how the world around us is represented in language and has as its core task to make possible that we can communicate in language about all thinkable happenings, experience, and ideas (Andersen \& Holsting, 2015, p. 61). Central to the experiential organizing of the language is the element process, surrounded by the elements participants and circumstances, called the transitivity system in SFL. In this system the process is at the core. Where process alone characterizes action, the configuration of process, participants, and circumstances realize an event, providing models for construing our experience of what goes on (Matthiessen \& Halliday, 2014, p. 220). The process is typically realized by a verbal group, the participants by nominal groups and the circumstances by adverbial groups or prepositional phrases. Processes characterize action and can be divided into mental processes (such as thinking, consciousness and inner symbolics), material processes ("doing," energy and change over time), verbal processes (communication and outer symbolic actions, "saying") and relational processes (no energy, no change over time, "to be" and "to have") (p. 64-65). 


\section{Overview of the analysis}

Above I have briefly outlined the experiential metafunction in SFL as a configuration of the elements process, participants, and circumstances. There are reasons to give focus to the element process in the present analysis, as the following overview of the analytical approach will explain. As mentioned, I started out by close reading the blog text, and based on the readings I hypothesized that the students developed a disciplinary language throughout the year of blog writing. This led me to approach the analysis in several steps, which will be detailed and discussed in the remainder of the article:

(i) The initial step was an exploratory word frequency analysis using the software application MAX QDA, to search for high frequent words and phrases across all the students. I also experimented with tagging and sorting words into categories for comparison from the beginning to the end of the academic year looking for changes in their use of disciplinary-specific terminology. This approach was problematic as sorting words into categories such as "every-day language" and "disciplinary language" was difficult to do reliably. By searching for words and phrases, I discovered a change in the distribution of the present tense forms of the verbs "er" (corresponds to am/is/are in English) and "har" (have/has in English $)^{1}$ from the texts in September to the texts in May. This led me to step two in the analysis, refining the initial hypothesis that the students develop a disciplinary language throughout the academic year: There is a shift in how the students use the transitivity system in their descriptions of their photos, indicating different ways of construing reality, occurring during the academic year, which suggests a change in language taking place from September to May.

(ii) Based on the findings in the first step, the second step was a closer look at the occurrences of to be and to have in the texts. Here, I found partial support for the hypothesis from (i); there is an increase in "have" from September to May and a decrease in "is" in the same time span. By analyzing word clusters in QDA MINER, patterns in how words group around forms of to be and to have lead me to detail this hypothesis further: In the texts that describe compositional choices, there seems to be a shift in the way the students position themselves in relation to their artwork in writing; the tendency is that [things] are in September, whereas [I] have [done things] in May.

(iii) The third step was to attempt to detail these findings by narrowing in on the texts from one of the students that is exemplary of the general trend in the material. I analyzed this student's texts from September to May in more detail, investigating more detailed the processes in her sentences that include to be and

\footnotetext{
${ }^{1}$ The Norwegian present simple forms "er" (Eng. is) and "har" (Eng. has) is, unlike English, not conjugated in person or number, and occurs just in these two forms across all persons, singular and plural. In the present material, "er" and "har" occur as am, are, is, have and has in the translated texts. For the sake of simplicity, I will refer to "er" and "har" as to be and to have, with the correct conjugations in the translated examples.
} 
to have. I also investigated the distribution of concrete and abstract nouns from September to May.

In step (i), I experimented with various ways of tagging lexical words in MAX QDA and sorting them into categories such as words pertaining to professional and private domains (e.g. words describing operations in Photoshop which can be linked to their school texts) to look for a change in their vocabulary during the academic year. Sorting words into such categories proved to be a difficult task, as it was difficult to group words pertaining to different domains reliably. The most notable pattern in step (i) was the difference in the distribution of verb forms, leading to a reformulation of my initial hypothesis in step (ii) as described above, and I did not find the approach where I grouped lexical words in categories reliable. Thus, for the rest of the article, I will detail (ii) to (iii), and discuss the results.

Step (ii) Word frequency analysis: to be and to have

Isolating the presentations of composition and performing a word frequency analysis on these parts of the texts reveals specific patterns in the usage of the verbs. As mentioned earlier, verb forms of to be and to have in the present tense show up as the most frequent verbs in the students' composition descriptions, as well as, not surprisingly, being among the most frequent words overall. In addition, usage of to have increase from September to May across all students, from 78 to 128 occurrences $(1,4 \%$ to $2,6 \%)$ in all tenses, and usage of to be decreased in the same time span, from 194 to 128 occurrences $(3,6 \%$ to $2,9 \%$ ) in all tenses (numbers are percentages of the total number of words in the text excerpts). There are still more occurrences of to be in all the examples, but the gap between to be and to have closed drastically from September to May (Figure 1). The occurrences of to have also increase more than to decrease, counting all students.

\section{To be and to have, numbers}

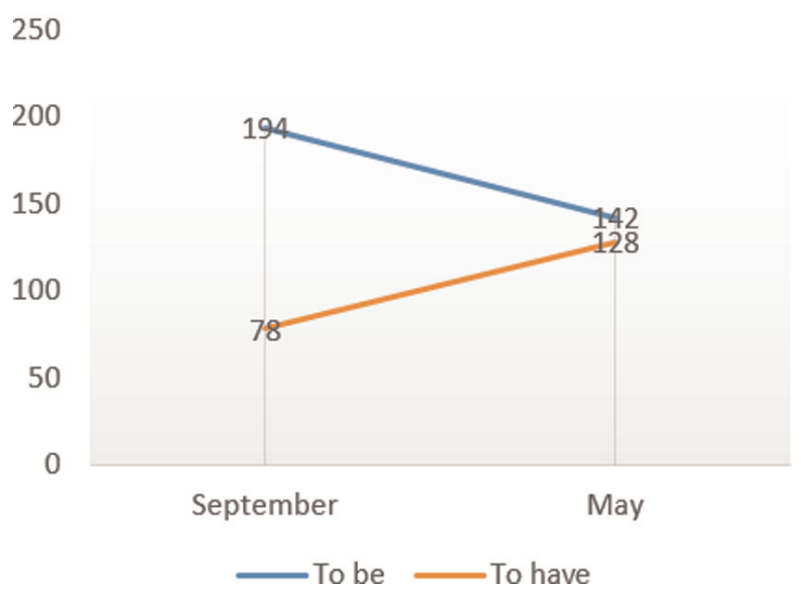

Figure 1. Occurrences of to be and to have from September to May. 
Expounding on Figure 1, I have used QDA MINER to illustrate in a dendrogram which words the forms of to be and to have appear close to in the students' texts (Table 1). In September, is (No. "er") appears as high frequent (size of left horizontal bars) in close relation (illustrated by closely grouped and narrow brackets) to high frequent words such as it (No. "det”), I (No. “jeg") and the picture (No. "bildet"). Have's (No. "har") brackets are wider to the right, denoting weaker connections to surrounding words.

In May, to the right in Table 1, have (No. "har") is closely related to high frequent words I (No. "jeg") and the picture (No. "bildet"). Is is grouped closely to It (No. "det"), as is the case in September, but more loosely connected to the picture (No. "bildet"), which is closer to has (No. "har") in this case. That is also the case for the pronoun I (No. "jeg”), being grouped relatively close to have (No. "har").

Table 1. Word clusters showing which words appear in connection with to be and to have.

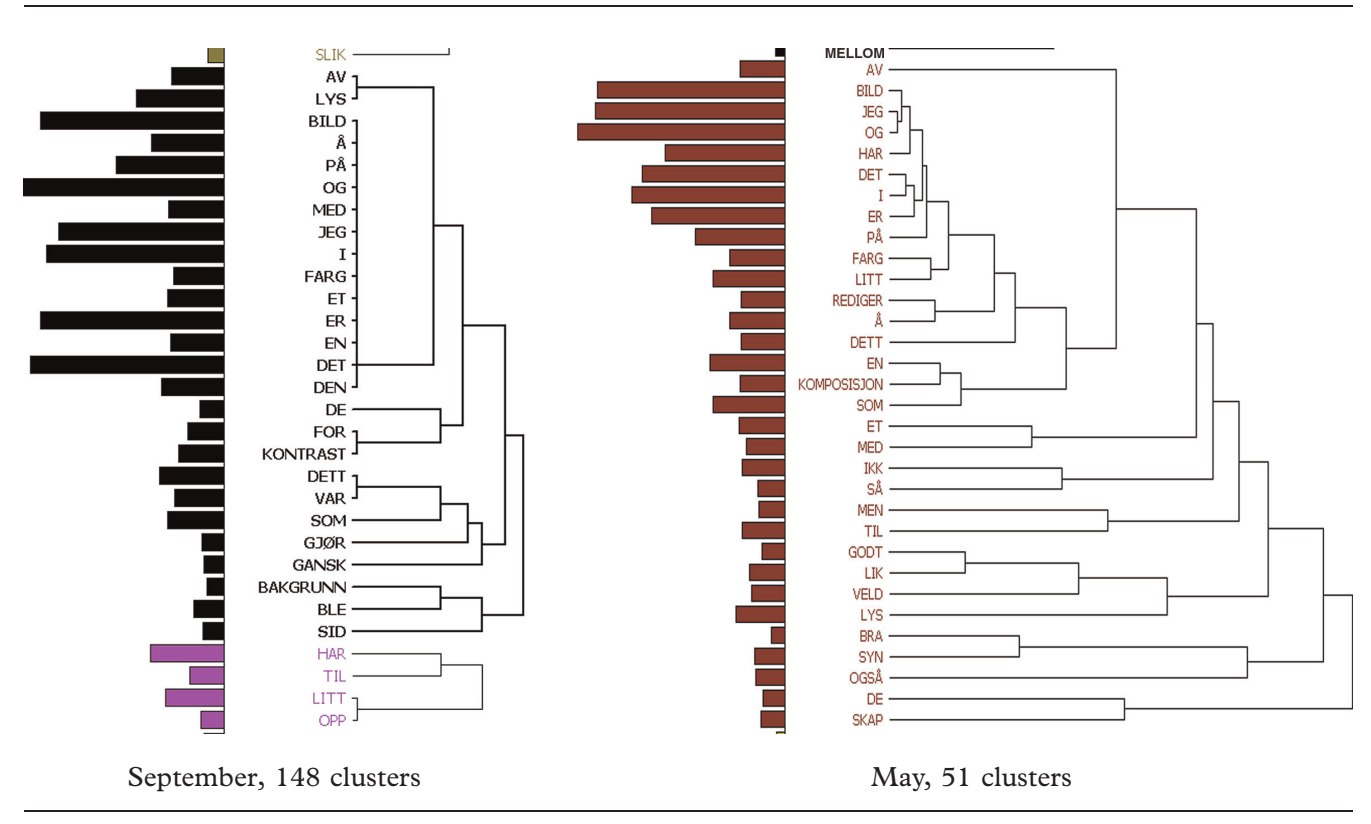

In September, there is a tight cluster including forms of to be in combination with high frequent words such as I, it and picture (No. "jeg," "det," and "bilde(t)." A similar and tight cluster is found around forms of to be in May as well, but here, forms of to have also compete with the attention, seemingly connected to $I$ and the picture.

To sum up, in concordance with what we have hypothesized so far, there is a tendency that [things] are in September, whereas [I] have [done things] in May.

\section{Individual student's choices}

Breaking down to each student the change in frequency between to be and to have from September to May, we can investigate the word frequency on the level of individual 
students. Most of the students follow the pattern of a decrease/increase of to have as discussed above, with some exceptions. ${ }^{2}$

To give depth to the general findings from the whole group, I have singled one student's (fictionalized as Christina) text as an example of a student text that follows the patterns discussed above, presuming that her text is representative of the general findings. Narrowing in on the texts from one student allows for a more detailed analysis of the language.

\section{Step (iii) Student text: Christina}

Christina is one of the students with a fair amount of stretch between forms of to be and to have in September and May, providing a good example of the general tendency in the material discussed so far. In these texts, to be occurs 18 times in September and 4 in May, whereas there are 11 occurrences of to have in September and 16 in May (Figure 1). ${ }^{3}$

The distribution of verbs in context in all occurrences in Christina's compositional sequences (cf. Table 2) can be illustrated like this, translated from Norwegian:

One main tendency in Christina's compositional sequences is the decrease in May of to be used lexically. In the material as a whole to be is used for the most part lexically, and mostly at the beginning of the academic year, describing features of the images or compositions ("The composition is simple /. ./ The background is unclear /. . . The leaves are yellow."). In May, to have increases significantly compared with September, and is used almost exclusively grammatically. Looking at the verbs used together with to have, they are verbs describing how the image is manipulated, that is, predominantly descriptions of the technical sides of composing a picture, involving procedures such as cropping or trimming an image, enhancing color, and so on.

The previous assumption suggesting a tendency that things are in September evolving into I have done something in May can be preliminary supported by looking in more detail at the verbs in context from the texts of one student. We see that the increase in use of to have towards May comes from utilizing have as an auxiliary verb to describe operations done to the picture (Table 2). In September, to be is used to describe qualities of the pictures/motives. In other words: there seems to be a change during the year from concrete descriptions of the pictures ("The background is unclear $/ . . /$ the leaves are yellow /.../ the picture is dark. ..") to describing action related to composing the picture ("I have edited /. . / I have used / . ./ I have enhanced"). This agrees with the initial, general findings in the entire material, where the broad word frequency searches, as well as visualizations across all blogs in general, follow this trend.

\footnotetext{
${ }^{2}$ In the case of to be, one student counters the tendency by nearly doubling the occurrences from September to May. In the case of to have, two students counter the tendency to increase the occurrences of to have and one student has only one occurrence of to have both in September and May. Still, the overall tendency, as described above, is clear, although investigating these exceptions to the general trend would have been an interesting study.

${ }^{3}$ Christina uses fewer words in the last assignment compared with the first, counting only the compositional parts, with 453 words in September and 383 words in May. This is concurrent with the entire student group decreasing from a total of 5332 words in September to 4762 words in May.
} 
Table 2. Distribution of verbs in context in Christinas compositional sequences of her texts.

\begin{tabular}{|c|c|}
\hline September & May \\
\hline To have $(\mathrm{n}=11)$ & To have $(\mathrm{n}=15)$ \\
\hline Grammatical function, auxiliary verb & Grammatical function, auxiliary verb \\
\hline $\begin{array}{l}\text { I have: enhanced } \times 2 \text { (two different expressions } \\
\text { difficult to translate to English), done, edited } \times 4 \text {, } \\
\text { taken, brought out, trimmed }\end{array}$ & $\begin{array}{l}\text { I have: edited } \times 8, \text { trimmed } \times 2 \text {, made [sharper], } \\
\text { used [the effect], trimmed, taken [a segment], } \\
\text { enhanced [the contrast] } \times 4 \text {, used [the techniques] } \\
\text { made [the colors warmer], adjusted [the contrasts] }\end{array}$ \\
\hline The leaves have: fallen [down] & We have: learned [about the techniques] \\
\hline Lexical function & Lexical function \\
\hline $\begin{array}{l}\text { The image has: [no particular composition] } \\
\text { Chosen to [not] have [anything particular in focus] }\end{array}$ & The image has: [exciting lines] \\
\hline To be $(\mathrm{n}=19)$ & To be $(\mathrm{n}=4)$ \\
\hline Grammatical function, auxiliary verb & Grammatical function, auxiliary verb \\
\hline $\begin{array}{l}\text { The image is: taken [in sunlight], taken [with a compact } \\
\text { camera] }\end{array}$ & $\begin{array}{l}\text { The image is: edited } \\
\text { The sharpness is: adjusted }\end{array}$ \\
\hline \multicolumn{2}{|l|}{ It is: taken [in sunlight] } \\
\hline Lexical function & Lexical function \\
\hline $\begin{array}{l}\text { The compositon is: simple } \times 3 \text {, not complicated, not } \\
\text { extremely complicated }\end{array}$ & $\begin{array}{l}\text { The colors are: much browner and warmer } \\
\text { The picture is: quite much warmer }\end{array}$ \\
\hline \multicolumn{2}{|l|}{ The background is: unclear $\times 2$} \\
\hline \multicolumn{2}{|l|}{ The cranberries are: in focus $\times 2$} \\
\hline \multicolumn{2}{|l|}{ The leaves are: yellow } \\
\hline \multicolumn{2}{|l|}{ The picture is: really pretty dark } \\
\hline \multicolumn{2}{|l|}{ It is: a bright and clear picture } \\
\hline \multicolumn{2}{|l|}{ I am: (pleased with the picture as it is) } \\
\hline \multicolumn{2}{|l|}{ This is: in reality only a small part of a large image } \\
\hline \multicolumn{2}{|l|}{ The light is: warm } \\
\hline I am: very pleased & \\
\hline
\end{tabular}

\section{Process types in Christina's compositional sequences}

As mentioned above, the distribution of to be and to have in Christina's texts is representative of the general class trend. In September, there are 19 occurrences of to be and 11 of to have, and in May, to be is reduced to 4 occurrences whereas there are 15 occurrences of to have. In other words, the most dramatic change here is the reduction of to be towards the end of the year, leaving forms of to have as dominant in the last 5 Categories assignment in May (Table 3).

Table 3. Occurrences of forms of to be and to have in Christina's texts in September and May.

\begin{tabular}{lll} 
& September & May \\
\hline To be & $\mathrm{N}=19$ & $\mathrm{~N}=4$ \\
To have & $\mathrm{N}=11$ & $\mathrm{~N}=15$ \\
\hline
\end{tabular}


Christina's to be-sentences in September: relational, attributive processes. In Christina's to be-sentences in September, to be is predominantly used lexically, typically in simple declaratives such as "The composition is very simple." This sentence exemplifies the relational processes that dominate these sentences. A relational process is characterized by two units that are brought in relation to each other in a way that one either classifies or describes the other. There are two participants in the sentence "The composition is very simple;" carrier and attribute, and the nominal "the composition" is the carrier and the adverbial group "very simple" is the attribute. The attribute type can either be classifying or descriptive, and in Christina's relational processes in her to be-sentences in May they are, with one exception, descriptive, as in this example, simply describing the carrier. Most often in Christina's case, the carrier is either a picture or a part of a picture, such as "the background."

There are a few exceptions to this pattern. In three occurrences, the verb to be is used grammatically rather than lexically, in all three cases together with the verb taken, forming a material action process, type creative, and all these sentences are configured like this: "the picture/it is taken." I will return to this process type under the description of the process types in May. In addition to these occurrences, in one single case departing from the relational attributive process type that dominates to be in September, to be is used in a relational existential process in the clause "... I am happy with it as it is."

However, the trend is that Christina uses to be a lot in September, predominantly in relational attributive processes. This process type, describing that something is or has something, is the place for the least dynamic and purely descriptive parts of the language (Andersen \& Holsting, 2015). In other words, the bulk of the use of to be in Christina's language in September seems to be merely qualitative assertions of her pictures; "The composition is very simple (...) The background is not clear (...) The leaves (...) are yellow." This indicates that these relatively non-dynamic qualitative assertions have a significant place in the language describing her images at the beginning of the academic year.

Christina's to have-sentences in September: material action processes. To have is less used than to be in Christina's compositional sentences in September, 11 versus 19, cf. Table 3, but there are nevertheless many instances of to have this month. In all instances except for one, to have is used grammatically, and in all the examples of the grammatical uses of to have except from one instance, the process is a material action process. The material processes realize descriptions of actions and events in the world, both concrete actions and happenings in physical and biological contexts, as well as a number of more abstract and non-observational connections in our world of perception (Andersen \& Holsting, 2015, p. 70). The space of sub-types of material processes is thus the most extensive pattern of processes in our language.

Consider the following two clauses from Christina's text:

a) "I have enhanced (no: "trukket opp") the contrasts somewhat ..." and

b) "I have taken the picture..." 
Actions are characterized by the participants' Actor and Goal, where the Actor does something to the Goal. In all but one of the to have-sentences in September, we find material action processes. There are two types of material action processes, creative and dispositive. The creative processes realize situations where Goal is the result of the process of which it is a part, and where Actor is the one creating something. Clause b) above might serve as an example of this, where Actor (I) has created Goal (the picture) by the process have taken (understood as photographed). Dispositive processes realize situations where Goal exists prior to the process of which it is a part, and where Actor handles the Goal, e.g. by changing it. Sentence a) is an example of the dispositive processes in Christina's text, where the Goal (the contrasts) already exist in the image and is manipulated by the Actor (I), manipulating the goal.

Both of these subtypes of material action processes, creative and dispositive, occur in a mixture in Christina's text. What they in sum contribute to are descriptions of Christina's actions on her images, either taking them or manipulating them in various ways. The Goals are primarily features of the images, and the Actor (here Christina) is the one doing things with the images. ${ }^{4}$

Christina's to be-sentences in May. As Table 3 shows, the occurrences of to be is dramatically reduced from September (19 occurrences) to May (4 occurrences). As we have seen in September, to be is used lexically, chiefly in relational attributive processes, serving to provide simple, qualitative assertions about her pictures. In May, of the four occurrences of to be, only two are used in relational attributive processes. The two remaining occurrences of to be is used grammatically, realizing the same process type as dominates her to have-sentences, the material action process type. Here, to be accompanies edited ("The picture is edited...") and enhanced ("The sharpness is enhanced. ..") in material action process of the dispositive type. In other words, the less dynamic and purely descriptive language of the to be sentences in the beginning of the academic year is significantly reduced towards the end of the year.

Christina's to have-sentences in May. There is an increase in to have-sentences in May (15 occurrences) compared with September (11 occurrences), but as we have seen, the to have-constructions by far outnumbers the to be-construction in May, with 15 to 4 in favor of the to have-constructions. Keeping in mind that the total number of words in Christina's compositional sequences decreases from 453 words in September to 383 words in May, it is reasonable to assume that the effect of the disproportion between to be and to have is noticeable in how Christina uses language to construe reality in this context. In other words, we can already here, based on what we know from the previous analysis, suspect that there is a change in

\footnotetext{
${ }^{4}$ There are two exceptions to this which can be mentioned; one clause where to have is used in a material process type describing an occurrence ("The leaves that have fallen down..."), and one clause where to have is used lexically in a relational attributive process ("The image has no particular composition").
} 
Christina's language from the start to the end of the academic year; she uses her language for different purposes in May compared to September.

The to have-sentences in May follow the same pattern as the to have-sentences in September. There is a clear dominance of material action processes, both creative and dispositive. The main verbs that accompany the auxiliary to have are more or less the same as in September, cf. Table 3 above. As discussed in the case of September, these constructions describe Christina's actions on her artwork, mainly different ways of editing, cropping and enhancing the images.

\section{Nouns: from concrete to abstract}

In addition to the verbs, I have tagged and sorted all nouns into two categories of abstract and concrete nouns to see if this contributes to a richer

\begin{tabular}{|c|c|c|c|c|}
\hline & 1 & 2 & Pearson's R & P value \\
\hline Har and combinations & $5,8 \%$ & $11,2 \%$ & $-1,000$ & ,000 \\
\hline Only Har & $0,5 \%$ & $0,5 \%$ & & \\
\hline Er and combinations & $1,5 \%$ & $1,0 \%$ & 1,000 & ,000 \\
\hline Only Er & $6,8 \%$ & $1,0 \%$ & 1,000 & ,000 \\
\hline Bilde and variants & $8,7 \%$ & $11,2 \%$ & $-1,000$ & ,000 \\
\hline Abstract Nouns & $8,3 \%$ & $8,3 \%$ & & \\
\hline Concrete Nouns & $23,8 \%$ & $11,7 \%$ & 1,000 & ,000 \\
\hline
\end{tabular}

Figure 2. Nouns sorted into categories of abstract and concrete nouns.

understanding of the change taking place in this text (Figure 2). Classifying nouns into categories such as abstract and concrete are not always clear-cut and in some cases subject to interpretation, depending on context and function. For instance, I have counted the nouns "background" and "foreground" as concrete nouns in this case, as I interpret these nouns as having the function of describing concrete parts of the picture, even though they can function as abstract nouns in other contexts. Similarly, "line" and "point" is counted as abstract nouns as they in this example refer to abstract compositional entities rather than actual shapes in the pictures. ${ }^{5}$ This analysis shows that the abstract nouns stay the same whereas there is a reduction of concrete nouns from September to May. Despite the fact that abstract nouns stay the same, the reduction of concrete nouns, in combination with the increase in processes discussing operations on the image, may suggest that the language changes towards a particular kind of abstraction; Photography is discussed more in terms of composition than objects in the image, and describing processes of doing things with the image (have

\footnotetext{
${ }^{5}$ I interpret the students using "line" to (functionally) describe a line that they e.g. draw themselves using a pen or a software tool as concrete, whereas when they use "line" to describe a branch from a tree somehow giving a direction or motion to the composition I interpret the use of "line" as abstract.
} 
edited, adjusted, cropped) rather than qualitative assertions (the background is unclear, the berry is in focus, the leaves are yellow).

\section{Discussion and Concluding Remarks}

Referring to the research question, the analysis suggests a change from the beginning to the end of the academic year in how the students construe a perspective on their role as participants in a discipline or profession. The main difference between September and May is in the relation between the constructions with to be and to have. As we have seen, constructions with to be is dramatically reduced from September to May. With this reduction, the relatively non-dynamic and descriptive relational attributive process types that were strongly present in Christina's language in September are almost absent in May. This leaves much more room for the material process types that dominate the rest of the constructions, both in the to have-sentences as in September, but also in two of the four to be-sentences in May. In other words, there is a general tendency in this material of a shift from the relational processes to the material processes from the start to the end of the academic year. This suggests a change in the way Christina construes reality from a rather non-vital, descriptive rendering of what is in the pictures she is discussing to a different perspective on herself as the one actively performing the changes.

In interpersonal and not merely ideational terms, the changes from the start to the end of the academic year in Christina's language may be characterized as a change of positions, from a spectator or observer to an active participant with a greater deal of responsibility, self-confidence and assertiveness. There is a difference in the kind of social relation she creates in this shift towards what we know from interviews with these students (Nygard, 2013, pp. 98-100) is a presumed audience where she towards the end has taken a different role as a professional, or established a different social role, as discussed in the analysis of her language. This could be described as a development of a kind of abstraction, a difference in how the students see an image, where they during an academic year learn to take command of the image in a shift from spectators to creators.

As mentioned earlier, one of the things the students discuss in interviews is the feeling of relevance in presenting their ideas and work both to a community of peers, as well as knowing their work is available to a greater public of interested readers (friends, family and other that might be interested in photography). It is not the scope of this article to claim that the changes the students display across the academic year is caused by the blog. But from an interpersonal perspective, it is hard to overlook the fact that they establish the practice of openly publishing their work as important to their blogging in interviews, explicitly describing the blog as a medium where they experience what they call freedom in writing, and accentuating the importance and sense of responsibility of publishing openly on the web, having an audience (Nygard, 2013, pp. 98-100). A central point is that the blog is not approached only as a supplement to traditional written activities. More so in many other cases of educational blogging, as discussed in the introduction, the blog is adapted to the 
classroom as a cultural phenomenon or a new, digital text culture in this class. As accounted for in Nygard (2013), the students see themselves as bloggers in this textcultural sense of the word, highly appreciating a type of literacy closely related to this text culture and the features for communication, sharing and organizing ideas that the blog as a technology for literacy enables for. At the very least it is plausible that there is a link between how they take authority in their own writing and their own responsibility towards their audience, a certain sense of interpersonal ethics in their communication on the terms of this material medium. This interpersonal awareness can be said to be an important part of their professional development throughout the academic year.

\section{Biography}

Arne Olav Nygard, PhD, is a lecturer at the Norwegian National Center for Reading Education and Research, University of Stavanger. He holds a Master's degree in Literacy Studies from the University of Stavanger. His field of research is the use of digital technologies for reading and writing in school.

\section{References}

Akbulut, Y. \& Kiyici, M. (2007). Instructional Use of Weblogs. Online Submission, 8(3), 6-15. Retrieved from http://eric.ed.gov/?id=ED498816

Amir, Z., Ismail, K. \& Hussin, S. (2011). Blogs in Language Learning: Maximizing Students' Collaborative Writing. Procedia - Social and Behavioral Sciences, 18, 537-543. https://doi.org/10.1016/j.sbspro.2011.05.079

Andersen, T. H. \& Holsting, E. M. (2015). Teksten i grammatikken (1st ed., Vol. 26). Odense: Syddansk Universitetsforlag.

Bakar, N. A., Latif, H. \& Ya'acob, A. (2010). ESL Students feedback on the use of blogs for language learning. 3L; Language, Linguistics and Literature, The Southeast Asian fournal of English Language Studies, 16(1), 120-141.

Barton, D. (2007). Literacy: an introduction to the ecology of written language (2nd ed.). Malden, Mass.: WileyBlackwell.

Blood, R. (2000). Weblogs: A History and Perspective. Retrieved April 2, 2014, from http://www.rebeccablood. net/essays/weblog_history.html

Chen, P. J. (2016). Learners' metalinguistic and affective performance in blogging to write. Computer Assisted Language Learning, 29(4), 790-814. https://doi.org/10.1080/09588221.2015.1068813

Chen, Y. L. Liu, E. Z. F. Shih, R. C., Wu, C. T. \& Yuan, S. M. (2011). Use of peer feedback to enhance elementary students' writing through blogging. British fournal of Educational Technology, 42(1), E1-E4. Retrieved from http://onlinelibrary.wiley.com/doi/10.1111/j.1467-8535.2010.01139.x/full

Doostdar, A. (2004). "The Vulgar Spirit of Blogging": On Language, Culture, and Power in Persian Weblogestan. American Anthropologist, 106(4), 651-662. https://doi.org/10.1525/aa.2004.106.4.651

Farmer, B. Yue, A. \& Brooks, C. (2008). Using blogging for higher order learning in large cohort university teaching: A case study. Australasian fournal of Educational Technology, 24(2), 123-136. Retrieved from http://citeseerx.ist.psu.edu/viewdoc/download?doi=10.1.1.553.8689\&rep=rep1\&type $=\mathrm{pdf}$

Fellner, T. \& Apple, M. (2006). Developing writing fluency and lexical complexity with blogs. The falt Call fournal, 2(1), 15-26.

Fischer, M. A. Haley, H. L. Saarinen, C. L. \& Chretien, K. C. (2011). Comparison of blogged and written reflections in two medicine clerkships. Medical Education, 45(2), 166-175. https://doi.org/10.1111/j.13652923.2010.03814.x

Grüters, R. (2011). Refleksjon i blogg: En hermeneutisk studie av refleksjon og dens tekstlige og retoriske manifestasjoner i en ny type skrive-og arkiveringsteknologi. Retrieved from http://brage.bibsys.no/xmlui/ handle/11250/244000

Juuhl, G. K. (2014). I det mykje skrivne : ei undersøking av ungdoms digitale tekstar $i$ skule og fritid som situerte, retoriske handlingar. Det humanistiske fakultet, Universitetet i Oslo. 


\section{Arne Olav Nygard}

Kjellberg, S. (2009). Blogs as Interfaces between Several Worlds. A Case Study of the Swedish Academic Blogosphere. Human IT, 10(3), 1-45.

Knain, E. (2014). Scientific Literacy for Participation: A Systemic Functional Approach to Analysis of School Science Discourses. Sense Publishers.

Lee, L. (2010). Fostering reflective writing and interactive exchange through blogging in an advanced language course. Recall, 22, 212-227. https://doi.org/10.1017/S095834401000008X

Maagerø, E. (2005). Språket som mening: innføring $i$ funksjonell lingvistikk for studenter og larere. Oslo: Universitetsforlaget.

Matthiessen, C. M. \& Halliday, M. A. K. (2014). Halliday's introduction to functional grammar (Fourth edition). London and New York: Routledge.

Miller, C. R. \& Shepherd, D. (2004). Blogging as Social Action: A Genre Analysis of the Weblog. Retrieved from http://conservancy.umn.edu/handle/11299/172818

Mortensen, T. E. (2008). Of a divided mind: Weblog literacy. Handbook of Research on Nerw Literacies. Mahwah, NJ: Erlbaum.

Novakovich, J. (2016). Fostering critical thinking and reflection through blog-mediated peer feedback. Fournal of Computer Assisted Learning, 32(1), 16-30. https://doi.org/10.1111/jcal.12114

Nygard, A. O. (2013). Perforating School. Digital Literacy in an Arts and Crafts Class. In J. A. Ávila \& J. Z. Pandya (Eds.), Critical Digital Literacies as Social Praxis (Vol. 54, pp. 87-106). New York: Peter Lang.

O’Donnell, M. (2006). Blogging as pedagogic practice: Artefact and ecology. Asia Pacific Media Educator, 1(17), 3.

Oravec, J. (2003). Blending by Blogging: weblogs in blended learning initiatives. Fournal of Educational Media, 28(2-3), 225-233. https://doi.org/10.1080/1358165032000165671

Rettberg, J. W. (2014). Blogging (2nd edition). Cambridge: Polity.

Soares, D. de A. (2008). Understanding class blogs as a tool for language development. Language Teaching Research, 12(4), 517-533. https://doi.org/10.1177/1362168808097165

Sullivan, M. \& Longnecker, N. (2014). Class blogs as a teaching tool to promote writing and student interaction. Australasian fournal of Educational Technology, 30(4), 390-401. Retrieved from https://www. learntechlib.org/p/148488/article_148488.pdf

Utecht, J. (2007). Blogs Aren't the Enemy; How Blogs Enhance Learning. Voices from Techlearning. com. Technology \& Learning, 27(9), 32. Retrieved from http://eric.ed.gov/?id=EJ776126

Vasudevan, L. Schultz, K. \& Bateman, J. (2010). Rethinking Composing in a Digital Age: Authoring Literate Identities Through Multimodal Storytelling. Written Communication, 27(4), 442-468. https://doi.org/10. 1177/0741088310378217

Wong, R. M. F. \& Hew, K. F. (2010). The impact of blogging and scaffolding on primary school pupils' narrative writing: A case study. International fournal of Web-Based Learning and Teaching Technologies, 5(2), 1-17. Retrieved from https://repository.nie.edu.sg/bitstream/10497/4480/1/IJWLTT-5-2-1_a.pdf 